\title{
A retrospective study of 120 cases of duodenal perforation
}

\author{
Dr R N Raikar ${ }^{1}$,Dr H Nagaraj ${ }^{2}$,Dr Rajalakshmi ${ }^{3}$,Dr Aneeta Mutgi ${ }^{4}$, \\ Dr Asha $\mathrm{M} \mathrm{N}^{5}$,Dr Arshiya Taj ${ }^{6}$. \\ Asisstant professor ,Department of General Surgery ,SIMS, Karnataka, India ${ }^{I}$ \\ Associate professor, Department of General Surgery, SIMS, Karnataka, India ${ }^{2}$ \\ Assistant professor, Department of General Surgery, SIMS, Karnataka, India ${ }^{3}$ \\ House surgeon SIMS, Karnataka, India ${ }^{4}$ \\ House surgeon ,SIMS, Karnataka, India ${ }^{5}$ \\ House surgeon ,SIMS, Karnataka, India ${ }^{6}$
}

\begin{abstract}
A retrospective study of 120 cases of duodenal perforation done between the years 2009 and 2011 to study the age incidence, sex preponderance, associated risk factors, complications, recovery time and mortality rate. A cross sectional retrospective and observational study involving 120 cases of duodenal perforation was conducted at SIMS \& RC, SHIMOGA. The study included cases admitted from $1^{\text {st }}$ October 2009 to $31^{\text {st }}$ September 2012.a total of 120 cases were evaluated with respect to age, sex, risk factors, complications, recovery time and mortality. After analysis we found that $88 \%$ were male and $12 \%$ were female. Age ranged from 20 -76 years. Peak age being 20-30 years and a second peak was noted between the ages 40-50 years. Associated risk factors were alcoholism (10.8\%), incomplete treatment for chronic gastritis(20.4\%), smoking (31.7\%) ,chronic NSAID drug users(35.8\%) . 92.7\% of the total cases had no complications in the post operative period, remaining $7.3 \%$ suffered complications like wound infection, ARDS and pelvic abscess. The recovery time ranged between 8-18 days and mortality rate was $1.4 \%$ in these patients. In the study we conducted we conclude that Duodenal perforations show male preponderance and high incidence in the $2^{\text {nd }}$ and $4^{\text {th }}$ decades and most common risk factors were NSAID users, incomplete treatment for chronic gastritis ,chronic bronchitis and alcoholism.post operative recovery took as min as 8 days and a maximum of 1 1/2month with complication majorly being wound infection. Mortality was as low as 2 out of 120 cases which could be avoided with early resuscitation of the patients in shock and taking them up for early surgery.
\end{abstract}

Keywords: duodenal perforations, duodenal ulcers, peritonitis, risk factors.

\section{Introduction}

Duodenal perforation is a most commonly encountered surgical emergency. Usually seen secondary to duodenal ulcer it causes leak of bile juice acid peptic juice and pancreatic juice into the general peritoneal cavity which causes peritoneal irritation followed by increased peritoneal fluid secretion which leads to easy invasion by bacteria leading to peritonitis within 12 hours of perforation ${ }^{1}$.

Ulcer perforation was a rare disease in the nineteenth century; however its incidence increased greatly at the turn of the twentieth century. Since then, the world has seen an epidemic of duodenal perforations among young men which now seems to be waning ${ }^{2-4]}$. The incidence of perforated peptic ulcer in Western countries varies between 7 to 9 cases per 100,000 populations per year ${ }^{[5]}$. Following the introduction of $\mathrm{H} 2-$ Receptor blockers and proton pump inhibitors, there has been a sharp decrease in elective peptic ulcer surgery. However, emergency operations for complications such as perforations are on the rise ${ }^{[6-7]}$. However on contradictory to our study an epidemiological change with increase in age and increase in the number of female patients has been noted $^{[8]}$. Free perforation into the general peritoneal cavity can be a catastrophic event, the signs and symptoms of which do not usually cause problems in diagnosis ${ }^{[9]}$. Once the diagnosis of perforation has been made, it is generally agreed that emergency surgery should be performed as soon as the patient has been adequately resuscitated ${ }^{[10]}$. Accepted therapeutic options are either simple closure or immediate definitive operation. Conservative treatment, originally proposed by Wangensteen, is reserved for patients considered to be too ill to stand the stress of surgery ${ }^{[4]}$. Simple closure of a perforated peptic ulcer is a standard operation at many centers as a quick straightforward procedure but might involve significant risk of later complications for recurrences ${ }^{[11]}$. Duodenal ulcer perforation is a common surgical emergency in our department, however most of the patients present late (usually after 2-3 days) because of illiteracy, poverty and ignorance. Hence it becomes important to determine the epidemiology and define the morbidity and mortality factors with respect to duodenal perforation.

\section{METHODS}

The study was a hospital based retrospective study done from $1^{\text {st }}$ October 2009 to $31^{\text {st }}$ September 2012.Inclusion criteria was all patients who were admitted in the emergency department with duodenal 
perforation.All the patients were retrospectively analyzed for the patient's particulars, intra-operative findings, surgery performed, post-operative stay, morbidity and mortality. Patients were diagnosed with perforated duodenal ulcer based on history, clinical examination, investigations and operative findings. After preliminary resuscitation and investigations, patients were taken for emergency surgery.

\section{FIGURES}
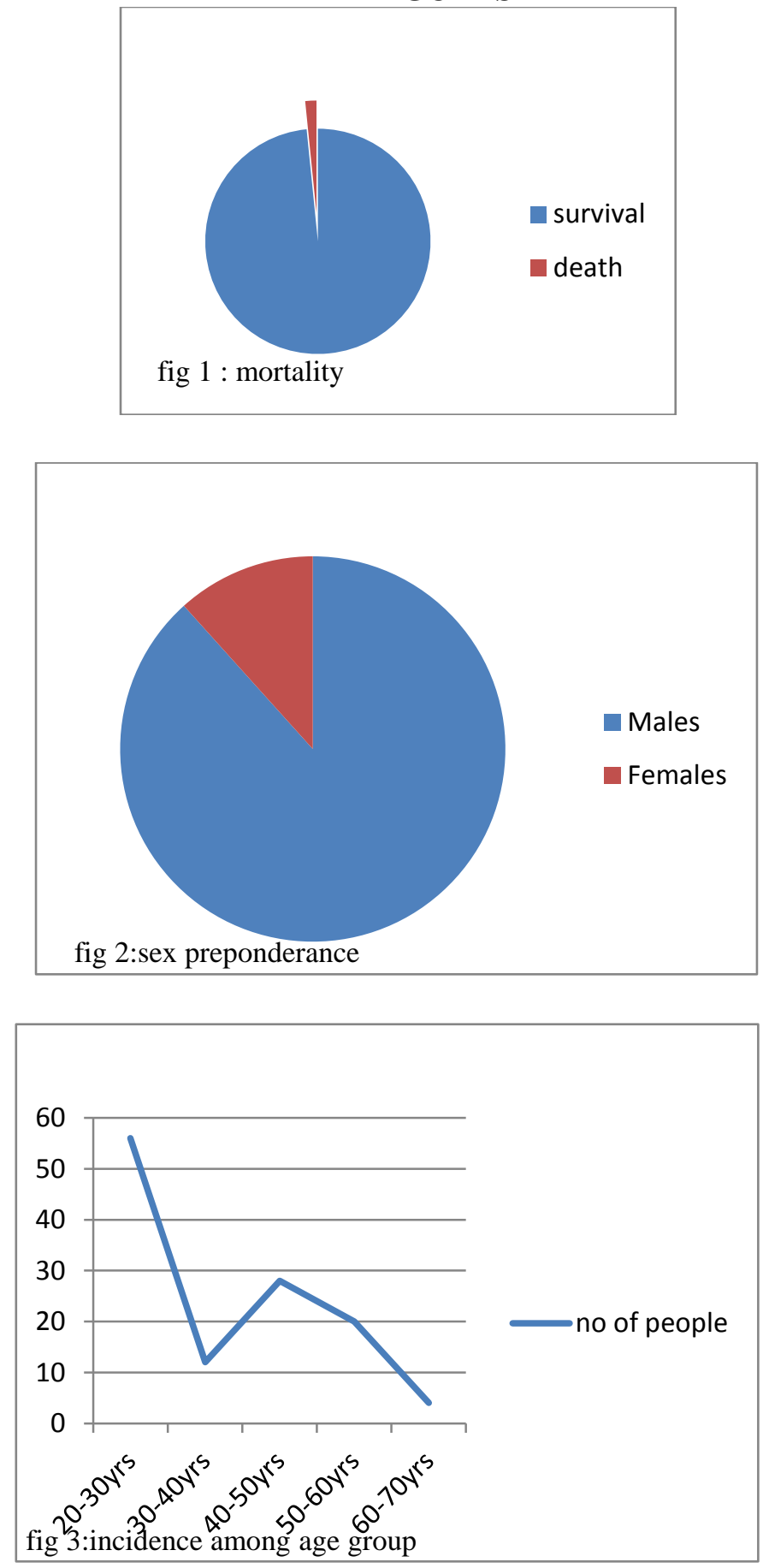


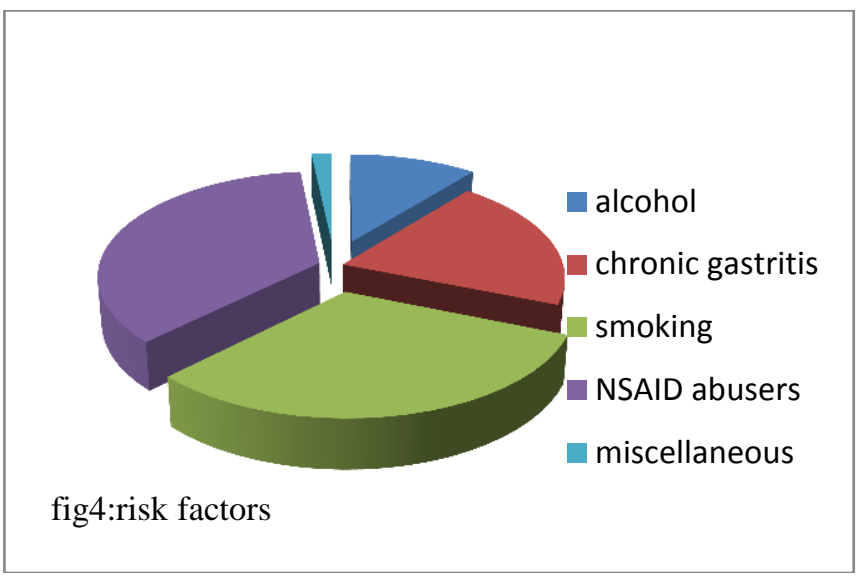

\section{DISCUSSION}

This study was conducted on 120 patients with perforated duodenal ulcers. Out of these 105(88\%) were males and $15(12 \%)$ were females; with the male: female ratio being 7:1. Age: The age of the patients presenting with perforated duodenal ulcers ranged between 20 to 76 years. Our study showed highest incidence in the $2^{\text {nd }}$ and $4^{\text {th }}$ decade of life. Out of these patients 56 patients were in the $2^{\text {nd }}$ decade, 12 patients were in $3^{\text {rd }}$ decade, 28 patients were in $4^{\text {th }}$ decade, 20 patients were in $5^{\text {th }}$ decade and 4 patients in $6^{\text {th }}$ decade. Occupation: All the 120 patients admitted were either farmers or coolie by occupation.Risk factors associated :Out of 120 cases studied 13 patients(10.8\%) gave history of chronic alcoholism (alcoholics for more than 10 years),25 patients(20.4\%) gave history of chronic gastritis and that they have been taking intermittent treatment for chronic gastritis, as many as 38(31.7\%) patients gave history of smoking , and there were 43patients were chronic NSAID drug users(35.8\%)The post operative recovery time of these patients ranged freom 8 days to 1 and half months. 37 patients(30.83\%) were discharged on 8 th postop day. $50.83 \%$ of patients 61 of them got discharged on $12^{\text {th }}$ post op day.13 patients $(10.83 \%)$ discharged at one month.and 7 patients $(5.83 \%)$ were discharged at 1 and half months. 2 patients died on $2^{\mathrm{ND}}$ an $3^{\mathrm{RD}}$ post operative day due to septicemic shock. The main reason for prolongation of hospital stay was due to post operative complications which included wound infections, pelvic abscess, lung infections.

\section{CONCLUSION}

Perforation is the most common emergency occurring in surgical practice and is the most encountered catastrophic complication of peptic ulcer. It is more prevalent in male patients and incidence highest in $2^{\text {nd }}$ decade. Most perforations are spontaneous but the risk significantly increases with use of NSAIDs, smoking, chronic gastritis and alcoholism. Although advances have been made in fields of surgery, anesthesia and modern ancillary facilities, duodenal perforations still assume life threatening dimensions. Omentopexy is a simple and safe procedure which can be performed in a very short time and is easy to perform; however, its immediate outcome is determined by more advanced age of patient, delay in admission, presence of associated diseases and shock on admission. Thus these factors need to be carefully taken into account in order to reduce morbidity and mortality. 


\section{REFERENCES}

[1] S. Das text book of surgery $6^{\text {th }}$ edition : Chapter - 36 : The stomach and duodenum : page no:735

[2] Svanes C. Lie R.T, Kavle G, Svanes K, Soreide O: Perforated peptic ulcer over 56 years; time treads in patient characteristics. Gut 1993; 34:1666-71.

[3] Coggon D, Lambert P, Langman MJS: 20 Years of hospital admission for peptic ulcer in England and Wales. Lancet 1983

[4] Somasekhar R Menakuru: Current management of Peptic Ulcer Perforations. Pak J Med Sci 2004; 20(2):157-63.

[5] Gupta BS, Talukaardar RN, Nepane HC: Cases of Medical science, Bharatpur over period of one year. Katmandu Univ Med J 2003; 3:166-169.

[6] Rajesh V. Chandra SS, Smile SR: Risk factors Predicting Operative mortality in perforated peptic ulcer disease. Trop Gastroenterol 2003; $24: 148-50$.

[7] Mohammad Haleem Taj, Din Mohammad, Shoaib Ahmed Qureshi: Outcome of Omentopexy as primary repair in perforated duodenal ulcer. J Coll Physicians Surg Pak 2007; 17(12):731-5.

[8] Primrose JN: Stomach and duodenum. In: Russel RCG,Willams NS,Bulstrode CJK,(EDI).Bailey and Love's Short practice of surgery, 24th ed. London; Arnold 2004;1026-61

[9] Caschieri A. Disorders of the stomach and duodenum. In: Cuschieri A, Steele RJC, Moosa AR, (EDI). Essential surgical practice, 4th ed. London; Arnold 2002; 261-319.

[10] Tanphiphat C, Tanprayoon T, Na Thalang A: Surgical treatment of perforated duodenal ulcer: A prospective trial between simple closure and definitive surgery. Br J Surg 1985; 72:370-372.

[11] Mehendale VG, Shenoy SN, Joshi AM, Chaudhari NC: Laparoscopic versus open surgical closure of perforated duodenal ulcers: a comparative study. Indian J Gastroenterol 2002; 21: 222-4.

[12] Lena GM, Blomgren MD: Long-term Results after Simple Closure in the Elderly. World J Surg 1997; 21(4): $412-415$. 